\title{
TEMPERATURE AND FUEL DEPENDENCE OF AN EQUIVALENT CIRCUIT MODEL OF DMFC DYNAMIC RESPONSE
}

\author{
Kshitiz Singh, ${ }^{*}$ Bill Diong, ${ }^{* *}$ Diego Estrada, ${ }^{*}$ and Bao Q. Nguyen**
}

\begin{abstract}
Fuel cells are increasingly important sources of electrical power as they can reduce the world's use of fossil fuels, leading to benefits such as decreased greenhouse gas emissions and cleaner air. However, their dynamic responses are slower than that of typical electrical and electronic systems drawing power from them. Hence, it is important to properly characterize an equivalent circuit model of the fuel cell's dynamic behaviour, for performing accurate analysis and optimal design of the power systems based on such sources. This paper describes a method of estimating the parameters of a second-order equivalent circuit model, a first-order model being less accurate, for the direct methanol fuel cell from measurements of its responses to step-changes in load at various temperatures, fuel flow rates and fuel concentrations. Analysis of these parameter values, which provided excellent fits of the test data, indicated that they are quite sensitive to temperature but relatively insensitive to fuel flow rates - more so for load-off than for load-on responses - for the same fuel concentration. Furthermore, different fuel concentrations resulted in greater variability of the parameter values during the load-on responses as compared to the load-off ones.
\end{abstract}

\section{Key Words}

Fuel cells, methanol, dynamic response, equivalent circuit model, parameter estimation

\section{Introduction}

Fuel cells are devices that convert the chemical energy of reactants into electricity, similar to a battery, with the difference that a fuel cell works on a continuous input of fuel and air to produce mainly electricity, water and heat. The different kinds of fuel cells include solid oxide fuel cells (SOFCs), proton exchange membrane fuel cells (PEMFCs) and direct methanol fuel cells (DMFCs), which operate most efficiently in different operating temperature ranges [1]; in particular, PEMFCs and DMFCs have low

\footnotetext{
* Department of Engineering, Texas Christian University, Fort Worth, TX, USA; e-mail: \{K.Singh, D.Estrada\}@tcu.edu

** School of Engineering, Southern Polytechnic State University, Marietta, GA, USA; e-mail: \{bdiong, bnguyen4\}@spsu.edu Recommended by Prof. P. Lund

(DOI: 10.2316/Journal.215.2014.3.215-1052)
}

operating temperature ranges, which is advantageous for many applications. However, methanol is easier to transport than the hydrogen used by PEMFCs and easier to work with, so DMFCs are an attractive option for various portable and mobile applications, such as powering military equipment, forklifts and scooters [2]-[4]. This paper will focus on DMFCs.

The DMFC has two inputs, a methanol solution of pre-determined concentration as fuel, and air; the outputs are unused methanol, water and small amounts of $\mathrm{CO}_{2}$. An important aspect of fuel cell technology is that the usual fuels are hydrogen and methanol, which can be readily produced from easily available domestic US resources, especially biomass [5]; this can help reduce US dependence on foreign oil. Whereas on a global basis, the benefits of increasing fuel cell use include decreased fossil fuel use, reduced greenhouse gas emissions and cleaner air. However, the dynamic responses of fuel cells are slower than that of typical electrical and electronic systems drawing power from them. Hence, it is important to properly characterize an equivalent circuit model of the DMFC's dynamic behaviour, for performing analysis and optimal design of the power systems based on such sources. Such characterization includes identifying the circuit's components, their connection and also the dependence of the component values on variable operating conditions such as temperature and fuel flow rate. The characterized model can then be used in several ways, such as for accurately evaluating and then improving how the DMFC interacts with other components of the complete power system (such as ultracapacitors and switch-mode power converters), for example, the effects of dc-ac converter ripple current on the lifespan of the fuel cell. Another way is to adjust, either statically or dynamically, and in either open-loop or closed-loop fashion, the temperature and/or fuel flow to obtain more optimal dynamic performance of DMFCs in applications with fast, frequent and/or significant load changes.

In the following, we will describe two such equivalent circuits, as well as the experimental dynamic response data we obtained that determined the particular circuit we would use for our study. Thereafter, we present the procedure used to estimate the component values of that 
equivalent circuit model and discuss the ensuing results, followed by several conclusions.

\section{Equivalent Circuit Models of DMFC Response}

Several equivalent circuit models have been proposed to model the dynamic response of $\mathrm{H}_{2}$-fuelled PEMFCs including [6], [7]. However, the model of [6] is a somewhat complex fourth-order circuit, whereas the model of [7] does not include an inductor component, which may be necessary for more accurate modelling of the DMFC under the broadest range of operating conditions as elaborated on below. Moreover, some of these models have been fit to, and its component values estimated from, measured frequency-domain (AC impedance) data with varying degrees of agreement [6], [7].

On the other hand, only a couple of equivalent circuits have been proposed specifically to model the dynamic response of DMFCs. Other kinds of models, such as those presented in [8]-[10], while important in their own right, are usually not as useful as circuit-type models to electrical engineers and control system engineers when they perform diagnostics, design or analysis, for example, to determine the amount of $\mathrm{AC}$ (ripple) current being drawn from the fuel cell by a given switch-mode $\mathrm{DC}-\mathrm{AC}$ converter, which affects the cell's lifespan.

The circuit model described in [11] for DMFCs is a first-order model (see Fig. 1) that has the following components: a source $E$ for the open-circuit voltage, which depends on the methanol and oxygen feed concentrations; a resistance $R_{a}$ representing the combined activation and mass transport losses; a capacitance $C$ for the double-layer capacitance of the electrodes and a resistance $R_{\text {ohmic }}$ representing the ohmic loss. In addition, second-order equivalent circuit models were proposed in [12], [13] (see Figs. 2 and 3, respectively). Note that the model described in [12] is identical to that in [13], except for the additional resistor representing cell ohmic resistance. The other components described in [13] to model the DMFC anode impedance are: an inductance $L$ to represent inductive behaviour (phase-delay) that can be explained using kinetic theory [14] for the reaction mechanism for methanol electrooxidation involving intermediate adsorbates, a behaviour confirmed by others such as [10]; a resistance $R_{O}$ that serves to modify the phase-delay according to the reaction scheme; a resistance $R_{\infty}$ that is associated with the part of the current response occurring without change in adsorbate coverage and a capacitance $C_{d}$ that is believed to be associated with the redistribution of charge at the anode (it depended on parameters such as current density) instead of double-layer capacitances of the DMFC anode and cathode, as the double-layer capacitance values for similar electrodes have been reported to be an order of magnitude lower than values calculated for this $C_{d}$. This circuit models well the frequency-domain impedance spectra of a DMFC operating with fuel flow at several times the stoichiometric rate, so excluding mass-transport limitations [13].

The model described in [12], based on the model of [13], includes an ohmic resistance $R_{\text {ohmic }}$, and a capacitance $C$ similar to $C_{d}$ of [13]; both of these values are supposedly

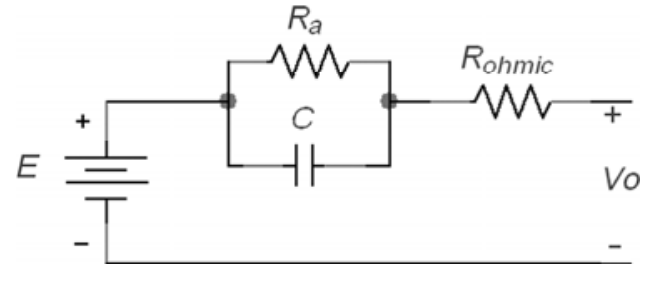

Figure 1. First-order equivalent circuit model of DMFC dynamic response, described in [11].

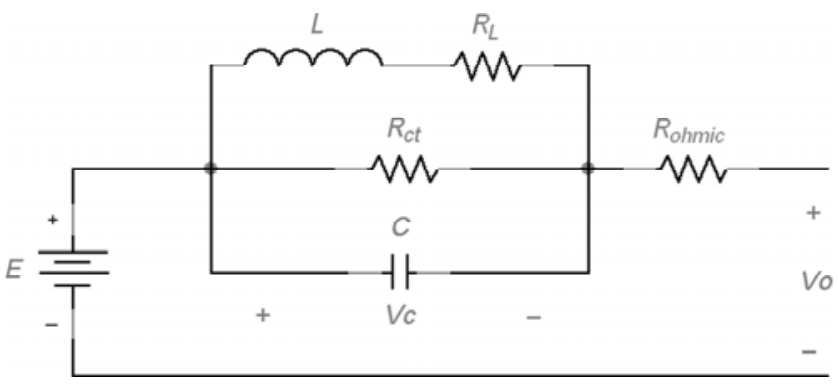

Figure 2. Second-order equivalent circuit model of DMFC dynamic response, described in [12].

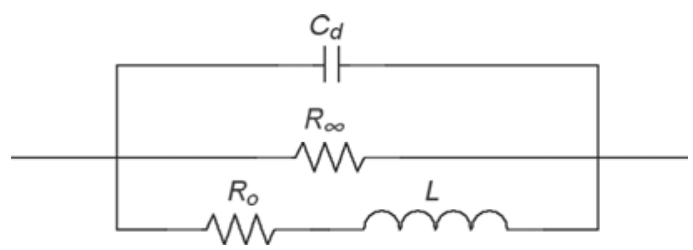

Figure 3. Second-order equivalent circuit model of DMFC dynamic response, described in [13].

constant. Based on impedance spectra measured with the cell output voltage at various levels from 0.5 to $0.1 \mathrm{~V}$, the authors of [12] also proposed nonlinear functions of current for the values of the parameters $R_{c t}, R_{L}$ and $L$, which are similar to $R_{\infty}, R_{o}$ and $L$, respectively, of [13].

\section{Testing of DMFC}

The tests were performed with the aid of a $850^{\circ} \mathrm{C}$ Integrated PEM fuel cell test station (FCTS) from Scribner Associates and a Gilson Minipuls 3 adjustable-speed peristaltic pump for controlling the flow rate of methanol solution (concentrations of $1 \mathrm{~mol} / \mathrm{l}$ and then $0.5 \mathrm{~mol} / \mathrm{l}$, the fuel being mixed from methanol (JT Baker, ACS reagent grade, $\geq 99.8 \%$ purity) and distilled water (Capitol Brand, ASTM Type II, ACS reagent grade, $>1 \mathrm{M} \Omega \mathrm{cm}$ resistivity) with the help of graduated polypropylene bottles, and then stored in them); see Fig. 4(a) and 4(b). The data for our study were acquired from a single-cell DMFC with a $25 \mathrm{~cm}^{2}$ active area pre-assembled membrane electrode assembly (MEA) constructed around a Nafion 117 membrane (E-Tek). The MEA also includes: (i) anode and cathode graphite compartments with mirror-image parallel channel, serpentine, flow fields; see Figs. 4(c); (ii) gold-plated current collector plates; (iii) aluminium end plates and bolts for holding the DMFC together and (iv) thermocouple probe, and heating elements, for closed-loop temperature regulation of the cell. 


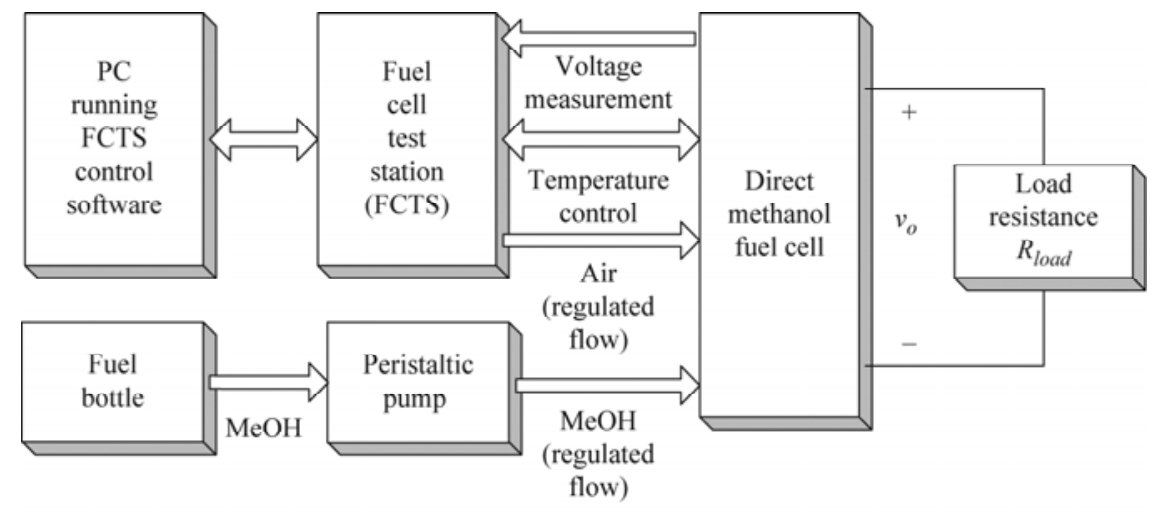

(a)

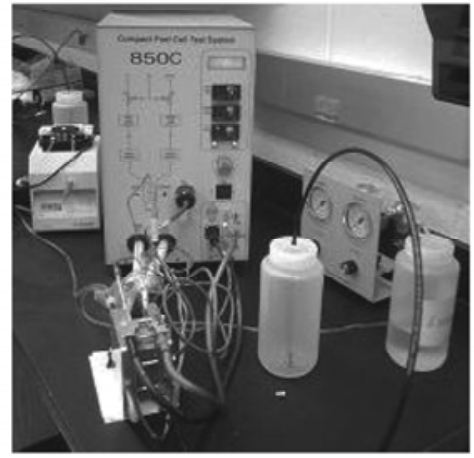

(b)

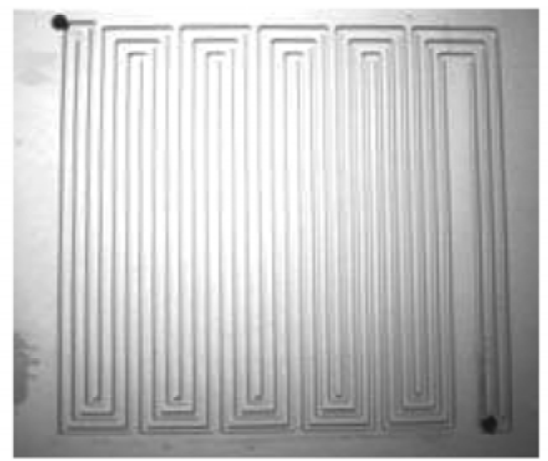

(c)

Figure 4. (a) Diagram of DMFC experimentation setup; (b) photo of DMFC experimentation setup; and (c) photo of DMFC anode compartment's flow field design.

We performed a series of experiments at different combinations of temperature and fuel flow rate. Tests were performed with temperature of the DMFC controlled to 30,50 and $70^{\circ} \mathrm{C}$ on separate occasions with the aid of a thermocouple and electric heating elements inserted into the DMFC end plates, allowing for closed-loop control by the Scribner FCTS software (version 3.80). We also varied the fuel flow rate at each temperature setting, using the same software interface, to be $0.2,0.4$ and then $0.6 \mathrm{ml} / \mathrm{min}$ on separate tests; however, the flow rate of air was fixed at $1 \mathrm{l} / \mathrm{min}$. Tests were conducted first with fuel having a concentration of $1 \mathrm{~mol} / \mathrm{l}$, and then on a different occasion with fuel having a concentration of $0.5 \mathrm{~mol} / \mathrm{l}$.

The tests consisted of applying a load resistance of $16 \Omega$ (actual value was $16.8 \Omega$ ) to the terminals of the fuel cell, while the FCTS software recorded the voltage values at these terminals at a $1 \mathrm{~Hz}$ rate. The test data were firstly of the voltage values across the DMFC terminals after the load resistance was connected to the fuel cell; this part of the fuel cell response will be referred to as the "load-on" response. After an interval of $5 \mathrm{~min}$, the load resistance was disconnected to produce an open circuit across the terminals, but the values for DMFC terminal voltage continued being recorded for another $5 \mathrm{~min}$; this portion of the test will be referred to as the "load-off" response. This load-on, load-off test was repeated for a total of three, sometimes four, times to ensure repeatability and also with the intent to average out the effect of random phenomena, such as electrical noise. As compared to circuit modelling using electrochemical impedance spectra data, which is a frequency-domain approach, this test procedure does not require an expensive $\mathrm{AC}$ impedance (frequency response) analyser. Instead, only time-domain data are collected.

Note that the choice of test conditions (temperature, fuel flow) was meant to obtain responses for a fairly wide range of possible operating conditions. Thus given the somewhat time-consuming nature of each load-on/load-off test (the duration of $5 \mathrm{~min}$ plus five more minutes for the cycle was selected to allow the two voltage responses to reach their steady states), which was performed manually and had to be repeated for averaging purposes, it was decided to use three (roughly low-medium-high) values for the temperature, and also three (roughly low-mediumhigh) values for the fuel flow, as test conditions. The choice of concentrations of 1 and $0.5 \mathrm{~mol} / \mathrm{l}$ was made mainly for the ease of obtaining those values given the limited precision of the volume measurements we were able to make using the graduated bottles available to us.

Figure 5 is illustrative of the measured load-on, loadoff responses at all nine operating conditions, though it was noted that the test data obtained at the $1 \mathrm{~mol} / 1,70^{\circ} \mathrm{C}$, $0.4 \mathrm{ml} / \mathrm{min}$ condition had somewhat greater variability (reduced repeatability) than the data at the other test conditions (the $R^{2}$ values comparing the data sets at a given condition to each other all being greater than 0.95 , where $R^{2}$ has its usual definition as the ratio of the sum of squares of the regression to the total sum of squares), which may explain certain results described in the next section; this was very likely due to random effects, and was not 


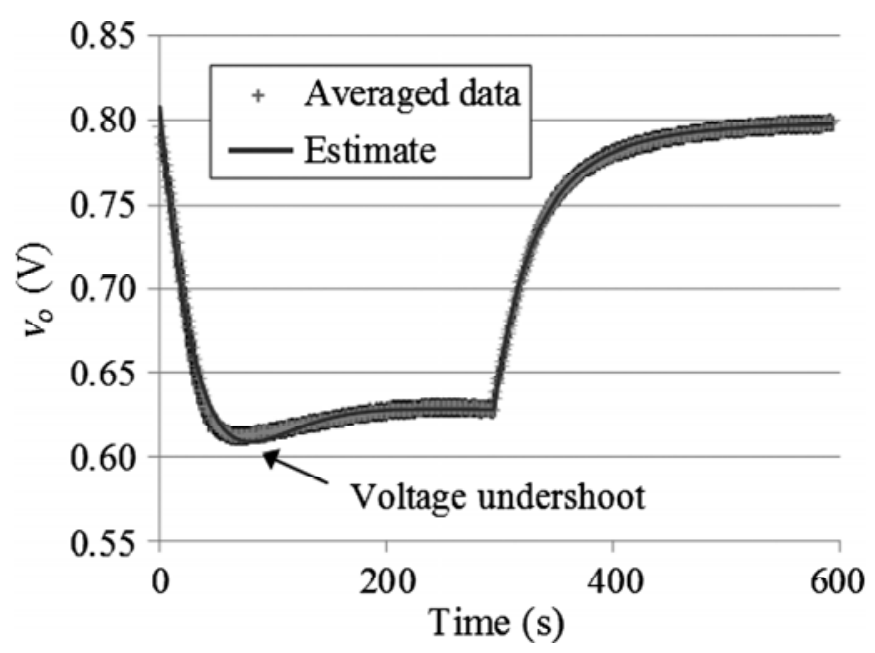

Figure 5. Comparison of averaged data (with error bars) of load-on/load-off response of DMFC output voltage for input of $1 \mathrm{~mol} / \mathrm{l}$ concentration methanol at $0.4 \mathrm{ml} / \mathrm{min}$, $50^{\circ} \mathrm{C}$, to its least-squares estimate.

especially grievous (the $R^{2}$ values comparing the three data sets at this one test condition to each other being $0.89,0.98$ and 0.84 ). We observed from these responses of the fuel cell output voltage that the load-on response typically had an undershoot - meaning the response's minimum value is less than its steady-state value. This type of response requires a mathematical function with at least two exponential terms to describe, which a first-order circuit cannot produce - its response, by definition, is a single exponential function of time [15]. Furthermore, small overshoots of a few millivolts - overshoot meaning the response's maximum value is greater than its steady-state value - were observed from the $0.5 \mathrm{~mol} / \mathrm{l}$ tests at $70^{\circ} \mathrm{C}$. It is uncertain, at this time, which of the several difference(s) between our tests and those in [11] result(s) in load-on responses with undershoots for us but (first-order) responses without undershoots in [11]. But these observed undershoots caused us to decide to focus on the second-order equivalent circuit model of Fig. 2 for our study.

It is well known that second-order circuits can yield a transient response that is either overdamped (sum of two real exponential responses) or underdamped (sum of two complex exponential responses, resulting in an exponentially damped sinusoidal response). From the collected data, it was clear that the load-off responses belonged to the overdamped category, while the load-on responses belonged to the underdamped category, so the corresponding capacitor voltage can be expressed as shown in (1) and (2), respectively,

$$
\begin{aligned}
& v_{c}(t)=a e^{b t}+c e^{d t} \\
& v_{c}(t)=\chi e^{-\alpha t} \cos (\omega t+\delta)+\Delta v
\end{aligned}
$$

where $v_{c}(t)$ is the capacitor voltage as indicated in Fig. 2, $t$ is time, $\Delta v$ is the voltage to which $C$ is charged to during the load-on response and the rest are constants that need to be determined from each test response. For both cases, the output voltage can be related readily to the capacitor voltage $v_{c}(t)$ by Kirchoff's voltage law, and so the load-on response is given by:

$$
v_{o}(t)=E-\left(a e^{b t}+c e^{d t}\right)-\left(v_{o}(t) / R_{L}\right) R_{o h m i c}
$$

and the load-off response is given by:

$$
v_{o}(t)=E-\left(\chi e^{-\alpha t} \cos (\omega t+\delta)+\Delta v\right)
$$

However, the crux of the problem is centred on estimating the parameters $(a, b, c, d)$ or $(\alpha, \omega, \chi, \delta)$ embedded in the capacitor voltage expression, as the voltage $E$ and resistance $R_{\text {ohmic }}$ can be readily obtained. Therefore, this guided our analysis, as described next, to relate the model component values to the parameters $(a, b, c, d)$ of (1) or $(\alpha, \omega, \chi, \delta)$ of $(2)$.

\section{Model Component Value Estimation}

First, the (either load-on or load-off) responses were averaged and then approximated by nonlinear least-squares curve-fitting using the Matlab ${ }^{\circledR}$ Curve Fitting Toolbox to determine the four response parameters, either $(a, b, c$, $d)$ of (1) or $(\alpha, \omega, \chi, \delta)$ of (2). Twenty-five iterations of each fitting were performed with different initial guesses of the parameter values to greatly increase the likelihood of obtaining the globally optimal solution. After selecting the best outcome of these iterations, we found that all of the $1 \mathrm{~mol} / \mathrm{l}$ load-on curves were fitted with $R^{2}>0.990$ with the exception of the $70^{\circ} \mathrm{C}, 0.4 \mathrm{ml} / \mathrm{min}$ case where the best fit yielded $R^{2}=0.961$. In addition, all of the $0.5 \mathrm{~mol} / \mathrm{l}$ load-on curves were fitted with $R^{2}>0.987$. Moreover, all of the $1 \mathrm{~mol} / \mathrm{l}$ load-off curves were fitted with $R^{2}>0.997$ with the exception of the $70^{\circ} \mathrm{C}, 0.4 \mathrm{ml} / \mathrm{min}$ case where the best fit yielded $R^{2}=0.990$. All of the $0.5 \mathrm{~mol} / \mathrm{l}$ load-off curves were fitted with $R^{2}>0.997$.

Next, the values for the passive elements of the model were derived. Before analysing this model, we checked and verified that the model would work as expected. In particular, at steady state the capacitor acts as an open circuit and the inductor $L$ acts as a short circuit, allowing all the current to go through it. Then, when the $R_{\text {load }}$ resistor is either connected or disconnected from the terminals of the fuel cell, the current through the inductor, and also the voltage drop across the capacitor, cannot change instantaneously.

To find the values for the capacitance, inductance and resistances in the circuit of Fig. 2, we made use of Laplace-domain circuit analysis with appropriate initial inductor current and initial capacitor voltage. For the load-off response, this analysis yielded an expression for the capacitor voltage that was of the form:

$$
V_{c}(s)=\frac{A_{1} s+A_{0}}{s^{2}+J_{1} s+J_{0}}
$$

where $A_{1}, A_{0}, J_{1}$ and $J_{0}$ are functions of $R_{c t}, R_{L}, L, C$ and/or $E$. Whereas for the load-on response, our circuit 
analysis yielded an expression for the capacitor voltage that was of the form:

$$
V_{c}(s)=\frac{-B_{1} s+B_{0}}{s^{2}+K_{1} s+K_{0}}+\frac{B_{1}}{s}
$$

where $B_{1}, B_{0}, K_{1}$ and $K_{0}$, are functions of $R_{c t}, R_{L}, L$, $C$ and/or $E$. Note also that the Laplace transform of (1) yields:

$$
V_{c}(s)=\frac{(a+c) s-(a d+b c)}{s^{2}-(b+d) s+b d}
$$

which is comparable to (5), whereas the Laplace transform of (2) yields:

$$
V_{c}(s)=\frac{\chi \cos (\delta) s+\chi[\alpha \cos (\delta)-\omega \sin (\delta)]}{s^{2}+2 \alpha s+\left(\alpha^{2}+\omega^{2}\right)}+\frac{\Delta v}{s}
$$

which is comparable to (6). For the load-on responses, $R_{\text {ohmic }}$ was easily calculated from the initial instantaneous drop in $v_{o}(t)$, as $v_{c}(t)$ cannot change instantaneously from its initial zero value, while matching expressions (6)-(8) resulted in four equations that depend nonlinearly on the to-be-determined $R_{c t}, R_{L}, L$ and $C$. They also depend on the known value of $E$, which is the open-circuit circuit voltage and also the initial value of the load-on response, and on the known value of $\Delta v$, which is the difference between the initial and final (steady-state) values of the load-on, and ideally also the load-off, responses. These component values were then estimated by the nonlinear least-squares approach, making use of the Matlab ${ }^{\circledR}$ Optimization Toolbox this time, and the results are presented in Table 1. Note that the estimations resulted in the sum of squared errors (SSE) being less than $2.63 \times 10^{-4}$ and $2.86 \times 10^{-5}$ for each of the nine $1 \mathrm{~mol} / \mathrm{l}$ and nine $0.5 \mathrm{~mol} / \mathrm{l}$ operating conditions, respectively.

For the load-off response, $R_{\text {ohmic }}$ could not be calculated, whereas matching expressions (5) and (7) resulted in one equation giving an exact solution for $R_{c t}$ and three equations that depended nonlinearly on the obtained $R_{c t}$, and the to-be-determined $R_{L}, L$ and $C$. The values of $R_{L}$, $L$ and $C$ were then estimated by the nonlinear least-squares approach, making use of the Matlab ${ }^{\circledR}$ Optimization Toolbox again, and the results are presented in Table 2. Note that the estimations resulted in the SSE being less than $3.92 \times 10^{-7}$ and $3.55 \times 10^{-7}$ for each of the nine $1 \mathrm{~mol} / \mathrm{l}$ and nine $0.5 \mathrm{~mol} / \mathrm{l}$ operating conditions, respectively.

\section{Estimated Model Component Value Results}

\subsection{For $1 \mathrm{~mol} / 1$ Fuel Concentration}

For the load-on response, the resistance $R_{c t}$ is essentially independent of the fuel flow rate between 0.2 and $0.6 \mathrm{ml} / \mathrm{min}$, but increases significantly with temperature between 30 and $70^{\circ} \mathrm{C}$. A mesh plot of the variation of $R_{c t}$ is shown as Fig. 6 for visualization purposes. The dependence of $R_{L}$ on temperature and fuel flow rate is quite similar to that of $R_{c t}$ except it showed a large abrupt increase at the $70^{\circ} \mathrm{C}$,
$0.4 \mathrm{ml} / \mathrm{min}$ operating condition; recall the test data at this condition had somewhat greater variability (reduced repeatability) than the data at other test conditions, so this increase may be slightly suspect. Interestingly, $L$ did not show much variation (in absolute terms) over the studied ranges of temperature and fuel flow rate. On the other hand, the estimates of $C$ varied widely in value and without discernible trend with respect to temperature or fuel flow rate.

For the load-off response, the resistance $R_{c t}$ is essentially independent over the range of temperature and fuel flow conditions. $R_{L}$ increases rather abruptly with temperature between 30 and $50^{\circ} \mathrm{C}$ then levels off, but is relatively independent of fuel flow rate. On the other hand, $C$ is essentially independent of fuel flow conditions but has an inverse dependency on temperature. $L$ also increases with temperature between 30 and $50^{\circ} \mathrm{C}$, but is relatively independent of fuel flow rate at these two temperatures; while at $70^{\circ} \mathrm{C}$, its values at both 0.2 and $0.6 \mathrm{ml} / \mathrm{min}$ have decreased from their values at $50^{\circ} \mathrm{C}$, but its value at $0.4 \mathrm{ml} / \mathrm{min}$ has instead increased from the value at $50^{\circ} \mathrm{C}$. As it was noted that the test data at this $70^{\circ} \mathrm{C}, 0.4 \mathrm{ml} / \mathrm{min}$ condition had somewhat greater variability (reduced repeatability) than the other test data, this inconsistent behaviour (greatly dissimilar from the 0.2 and $0.6 \mathrm{ml} / \mathrm{min}$ values) is again slightly suspect, and needs to be confirmed in future studies.

\subsection{For $0.5 \mathrm{~mol} / 1$ Fuel Concentration}

For the load-on response, the resistances $R_{c t}$ and $R_{o h m i c}$ are essentially independent of the fuel flow rate between 0.2 and $0.6 \mathrm{ml} / \mathrm{min}$, and of the temperature between 30 and $70^{\circ} \mathrm{C}$, although $R_{c t}$ varies somewhat more than $R_{o h m i c}$. Furthermore, the $R_{\text {ohmic }}$ values are very much consistent with those obtained from the $1 \mathrm{~mol} / \mathrm{l}$ tests, as expected. The $L$ values varied slightly more than the $C$ values (in absolute and percentage terms) over the studied ranges of temperature and fuel flow rate, although both were without discernible trend with respect to temperature or fuel flow rate. Compared to the $1 \mathrm{~mol} / \mathrm{l}$ results, the $L$ values had increased by an order of magnitude, while the $C$ values had decreased by at least one order of magnitude, so these are significantly affected by the fuel concentration.

For the load-off response, the resistance $R_{c t}$ is essentially independent over the range of temperature and fuel flow conditions, and also very much consistent with those obtained from the $1 \mathrm{~mol} / \mathrm{l}$ tests. $R_{L}$ increases rather abruptly with temperature between 30 and $50^{\circ} \mathrm{C}$ then levels off; however, it is relatively independent of fuel flow rate at 50 and $70^{\circ} \mathrm{C}$, just like the $1 \mathrm{~mol} / \mathrm{l}$ case. On the other hand, $C$ is essentially independent of fuel flow conditions at 50 and $70^{\circ} \mathrm{C}$, but has an inverse dependency on temperature (see Fig. 7), just like the $1 \mathrm{~mol} / \mathrm{l}$ cases. $L$ also increases with temperature between 30 and $50^{\circ} \mathrm{C}$ to become somewhat independent of fuel flow rate at $50^{\circ} \mathrm{C}$, although curiously its values for the $30^{\circ} \mathrm{C} 0.4 \mathrm{ml} / \mathrm{min}$ and $30^{\circ} \mathrm{C} 0.6 \mathrm{ml} / \mathrm{min}$ cases are two orders of magnitude lower than for the other cases, which values are in line with the $L$ values for the $1 \mathrm{~mol} / \mathrm{l}$ condition. 
Table 1a

Second-Order Equivalent Circuit Model [12] Component Values, Estimated from DMFC Output Voltage Load-On Responses at Various Temperatures and (1 mol/l Concentration) Fuel Flow Rates

\begin{tabular}{|c|c|c|c|c|c|c|c|c|c|}
\hline & \multicolumn{3}{|c|}{$R_{c t}(\Omega)$} & \multicolumn{3}{|c|}{$R_{L}(\Omega)$} & \multicolumn{3}{|c|}{$L(\mathrm{H})$} \\
\hline & $0.2 \mathrm{ml} / \mathrm{min}$ & $0.4 \mathrm{ml} / \mathrm{min}$ & $0.6 \mathrm{ml} / \mathrm{min}$ & $0.2 \mathrm{ml} / \mathrm{min}$ & $0.4 \mathrm{ml} / \mathrm{min}$ & $0.6 \mathrm{ml} / \mathrm{min}$ & $0.2 \mathrm{ml} / \mathrm{min}$ & $0.4 \mathrm{ml} / \mathrm{min}$ & $0.6 \mathrm{ml} / \mathrm{min}$ \\
\hline $30^{\circ} \mathrm{C}$ & 1.495 & 1.555 & 2.502 & 45.22 & 52.14 & 88.73 & 3.611 & 3.336 & 2.456 \\
\hline $50^{\circ} \mathrm{C}$ & 4.676 & 5.847 & 7.959 & 141.2 & 173.1 & 308.0 & 2.534 & 2.689 & 4.122 \\
\hline \multirow[t]{3}{*}{$70^{\circ} \mathrm{C}$} & 18.39 & 21.64 & 15.23 & 578.2 & 1006 & 341.1 & 1.651 & 2.717 & 1.209 \\
\hline & \multicolumn{3}{|c|}{$C(\mathrm{~F})$} & \multicolumn{3}{|c|}{$R_{\text {ohmic }}(\Omega)$} & & & \\
\hline & $0.2 \mathrm{ml} / \mathrm{min}$ & $0.4 \mathrm{ml} / \mathrm{min}$ & $0.6 \mathrm{ml} / \mathrm{min}$ & $0.2 \mathrm{ml} / \mathrm{min}$ & $0.4 \mathrm{ml} / \mathrm{min}$ & $0.6 \mathrm{ml} / \mathrm{min}$ & & & \\
\hline $30^{\circ} \mathrm{C}$ & 43945 & 18041 & 36807 & 0.1512 & 0.1277 & 0.1073 & & & \\
\hline $50^{\circ} \mathrm{C}$ & 2015 & 766.3 & 22.85 & 0.1300 & 0.1558 & 0.1699 & & & \\
\hline $70^{\circ} \mathrm{C}$ & 34.80 & 29.80 & 364.8 & 0.1220 & 0.1241 & 0.1613 & & & \\
\hline
\end{tabular}

Table $1 \mathrm{~b}$

Second-Order Equivalent Circuit Model [12] Component Values, Estimated from DMFC Output Voltage Load-Off Responses at Various Temperatures and (1 mol/l Concentration) Fuel Flow Rates

\begin{tabular}{|c|c|c|c|c|c|c|c|c|c|}
\hline & \multicolumn{3}{|c|}{$R_{c t}(\Omega)$} & \multicolumn{3}{|c|}{$R_{L}(\Omega)$} & \multicolumn{3}{|c|}{$L(\mathrm{H})$} \\
\hline & $0.2 \mathrm{ml} / \mathrm{min}$ & $0.4 \mathrm{ml} / \mathrm{min}$ & $0.6 \mathrm{ml} / \mathrm{min}$ & $0.2 \mathrm{ml} / \mathrm{min}$ & $0.4 \mathrm{ml} / \mathrm{min}$ & $0.6 \mathrm{ml} / \mathrm{min}$ & $0.2 \mathrm{ml} / \mathrm{min}$ & $0.4 \mathrm{ml} / \mathrm{min}$ & $0.6 \mathrm{ml} / \mathrm{min}$ \\
\hline $30^{\circ} \mathrm{C}$ & 1.020 & 1.023 & 1.024 & 21.14 & 26.51 & 18.16 & 1895 & 2569 & 1653 \\
\hline $50^{\circ} \mathrm{C}$ & 1.006 & 1.003 & 1.007 & 84.44 & 79.55 & 84.68 & 3924 & 3984 & 4738 \\
\hline \multirow[t]{3}{*}{$70^{\circ} \mathrm{C}$} & 0.9832 & 0.9664 & 0.9835 & 85.80 & 97.24 & 89.78 & 2304 & 10124 & 2813 \\
\hline & \multicolumn{3}{|c|}{$C(\mathrm{~F})$} & & & & & & \\
\hline & $0.2 \mathrm{ml} / \mathrm{min}$ & $0.4 \mathrm{ml} / \mathrm{min}$ & $0.6 \mathrm{ml} / \mathrm{min}$ & & & & & & \\
\hline $30^{\circ} \mathrm{C}$ & 67.88 & 69.74 & 68.93 & & & & & & \\
\hline $50^{\circ} \mathrm{C}$ & 36.55 & 37.72 & 36.25 & & & & & & \\
\hline $70^{\circ} \mathrm{C}$ & 22.50 & 22.48 & 20.92 & & & & & & \\
\hline
\end{tabular}

Finally, in broadly comparing the component values for the $1 \mathrm{~mol} / \mathrm{l}$ cases to the $0.5 \mathrm{~mol} / \mathrm{l}$ cases, it appears that the higher fuel concentration resulted in greater variability of those values. This comparison is between the values for the various temperature and fuel flow-rate conditions, as well as between the values for the load-on and load-off responses.

\section{Further Discussion}

Muller et al. [13] presented values of $C=0.135 \mathrm{~F} / \mathrm{cm}^{2}$, $R_{c t}=1.705 \Omega-\mathrm{cm}^{2}, \quad R_{L}=0.863 \Omega-\mathrm{cm}^{2}$ and $L=0.716 \mathrm{H} /$ $\mathrm{cm}^{2}$, obtained under load, for their proposed second-order model (Fig. 3), estimated using frequency-domain (AC impedance) data and technique. For a $25 \mathrm{~cm}^{2}$ active area membrane, these would correspond to $C=3.375 \mathrm{~F}$, $R_{c t}=68.2 \mathrm{~m} \Omega, \quad R_{L}=34.5 \mathrm{~m} \Omega$ and $L=17.9 \mathrm{H}$. Comparison of these values to the corresponding estimates in Tables 1a and 2a (under load) yields average percentage errors of $\{12819 \%, 880315 \%,-85 \%,-335790 \%\}$ and $\{20118 \%, 3699 \%, 122 \%, 156 \%\}$, respectively, for $R_{c t}, R_{L}$, $L$ and $C$. The likely explanation for the large discrepancies is that the operating conditions in [13] differ significantly in a few key respects from the operating conditions used in our study; in particular, the lowest current density in their tests was $100 \mathrm{~mA} / \mathrm{cm}^{2}$, although it is not completely clear from [13] which set of data (and operating conditions) corresponded to their estimates as given above, while our tests were at a current density of about $2 \mathrm{~mA} / \mathrm{cm}^{2}$. These parameters' dependence on current was described in [12].

On the other hand, let us consider the output impedances corresponding to our obtained parameter estimates. The output impedance of the studied second-order equivalent circuit model (Fig. 2) is expressed as:

$$
Z=R_{\text {ohmic }}+\frac{R_{c t} L s+R_{c t} R_{L}}{R_{c t} L C s^{2}+\left(L+R_{c t} R_{L} C\right) s+\left(R_{c t}+R_{L}\right)}
$$


Table 2a

Second-Order Equivalent Circuit Model [12] Component Values, Estimated from DMFC Output Voltage Load-On Responses at Various Temperatures and (0.5 mol/l Concentration) Fuel Flow Rates

\begin{tabular}{|c|c|c|c|c|c|c|c|c|c|}
\hline & \multicolumn{3}{|c|}{$R_{c t}(\Omega)$} & \multicolumn{3}{|c|}{$R_{L}(\Omega)$} & \multicolumn{3}{|c|}{$L(\mathrm{H})$} \\
\hline & $0.2 \mathrm{ml} / \mathrm{min}$ & $0.4 \mathrm{ml} / \mathrm{min}$ & $0.6 \mathrm{ml} / \mathrm{min}$ & $0.2 \mathrm{ml} / \mathrm{min}$ & $0.4 \mathrm{ml} / \mathrm{min}$ & $0.6 \mathrm{ml} / \mathrm{min}$ & $0.2 \mathrm{ml} / \mathrm{min}$ & $0.4 \mathrm{ml} / \mathrm{min}$ & $0.6 \mathrm{ml} / \mathrm{min}$ \\
\hline $30^{\circ} \mathrm{C}$ & 6.672 & 23.68 & 11.08 & 0.2688 & 0.8142 & 0.5192 & 26.27 & 36.36 & 42.34 \\
\hline $50^{\circ} \mathrm{C}$ & 5.276 & 32.09 & 33.72 & 0.3887 & 0.6756 & 0.8233 & 21.27 & 18.66 & 23.17 \\
\hline \multirow[t]{3}{*}{$70^{\circ} \mathrm{C}$} & 1.705 & 2.921 & 6.951 & 4.117 & 0.9121 & 3.276 & 102.8 & 22.86 & 63.15 \\
\hline & \multicolumn{3}{|c|}{$C(\mathrm{~F})$} & \multicolumn{3}{|c|}{$R_{\text {ohmic }}(\Omega)$} & & & \\
\hline & $0.2 \mathrm{ml} / \mathrm{min}$ & $0.4 \mathrm{ml} / \mathrm{min}$ & $0.6 \mathrm{ml} / \mathrm{min}$ & $0.2 \mathrm{ml} / \mathrm{min}$ & $0.4 \mathrm{ml} / \mathrm{min}$ & $0.6 \mathrm{ml} / \mathrm{min}$ & & & \\
\hline $30^{\circ} \mathrm{C}$ & 6.653 & 5.130 & 4.524 & 0.1226 & 0.1456 & 0.1575 & & & \\
\hline $50^{\circ} \mathrm{C}$ & 9.329 & 9.320 & 8.463 & 0.1553 & 0.1397 & 0.1272 & & & \\
\hline $70^{\circ} \mathrm{C}$ & 19.30 & 9.141 & 5.885 & 0.1583 & 0.1827 & 0.1660 & & & \\
\hline
\end{tabular}

Table 2b

Second-Order Equivalent Circuit Model [12] Component Values, Estimated from DMFC Output Voltage Load-Off Responses at Various Temperatures and (0.5 mol/l Concentration) Fuel Flow Rates

\begin{tabular}{|c|c|c|c|c|c|c|c|c|c|}
\hline & \multicolumn{3}{|c|}{$R_{c t}(\Omega)$} & \multicolumn{3}{|c|}{$R_{L}(\Omega)$} & \multicolumn{3}{|c|}{$L(\mathrm{H})$} \\
\hline & $0.2 \mathrm{ml} / \mathrm{min}$ & $0.4 \mathrm{ml} / \mathrm{min}$ & $0.6 \mathrm{ml} / \mathrm{min}$ & $0.2 \mathrm{ml} / \mathrm{min}$ & $0.4 \mathrm{ml} / \mathrm{min}$ & $0.6 \mathrm{ml} / \mathrm{min}$ & $0.2 \mathrm{ml} / \mathrm{min}$ & $0.4 \mathrm{ml} / \mathrm{min}$ & $0.6 \mathrm{ml} / \mathrm{min}$ \\
\hline $30^{\circ} \mathrm{C}$ & 0.9997 & 0.9566 & 0.9606 & 14.33 & 0.7226 & 4.956 & 2093 & 12.54 & 65.09 \\
\hline $50^{\circ} \mathrm{C}$ & 0.9976 & 1.001 & 0.9999 & 98.99 & 99.11 & 99.44 & 5014 & 4899 & 5451 \\
\hline \multirow[t]{3}{*}{$70^{\circ} \mathrm{C}$} & 0.9831 & 0.9770 & 0.9396 & 99.09 & 99.50 & 97.64 & 3873 & 2081 & 13024 \\
\hline & \multicolumn{3}{|c|}{$C(\mathrm{~F})$} & & & & & & \\
\hline & $0.2 \mathrm{ml} / \mathrm{min}$ & $0.4 \mathrm{ml} / \mathrm{min}$ & $0.6 \mathrm{ml} / \mathrm{min}$ & & & & & & \\
\hline $30^{\circ} \mathrm{C}$ & 84.17 & 228.0 & 118.6 & & & & & & \\
\hline $50^{\circ} \mathrm{C}$ & 39.74 & 38.49 & 38.06 & & & & & & \\
\hline $70^{\circ} \mathrm{C}$ & 22.73 & 20.23 & 24.74 & & & & & & \\
\hline
\end{tabular}

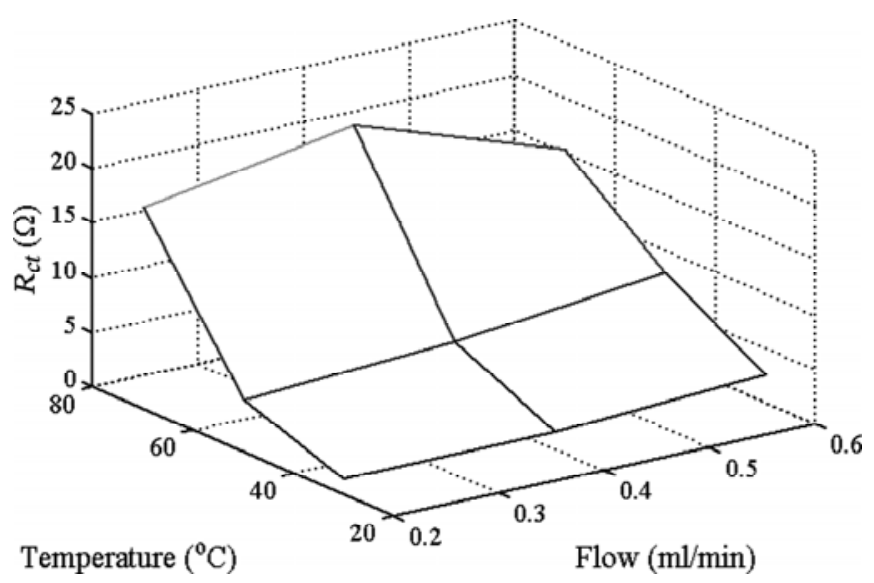

Figure 6. Dependence of resistance $R_{c t}$ values, estimated from load-on step-responses, on temperature and (1 mol/l concentration) fuel flow rate.

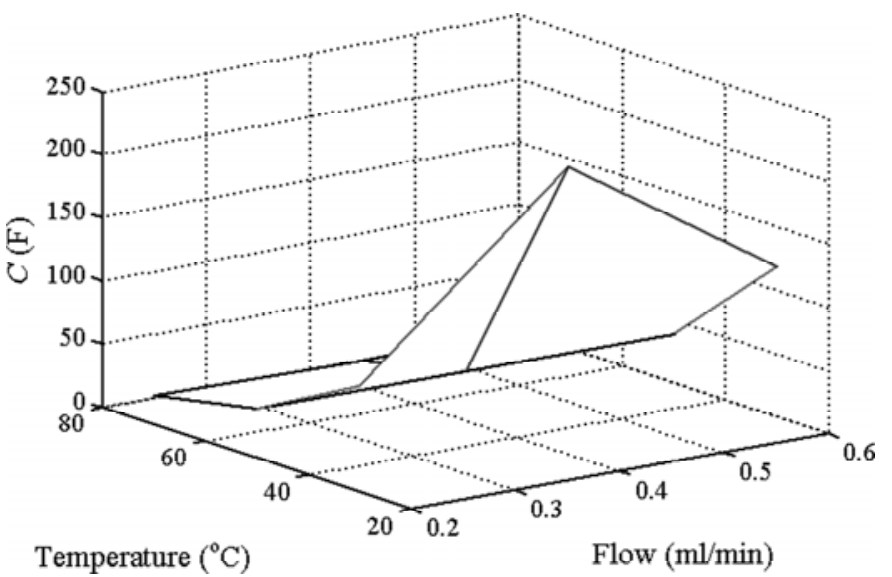

Figure 7. Dependence of capacitance $C$ values, estimated from load-off step-responses, on temperature and $(0.5 \mathrm{~mol} / \mathrm{l}$ concentration) fuel flow rate. 


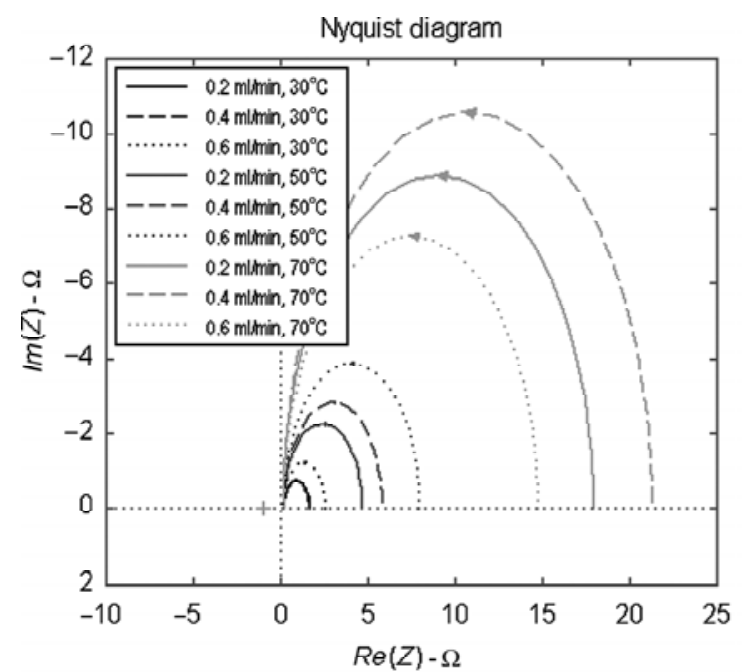

(a)

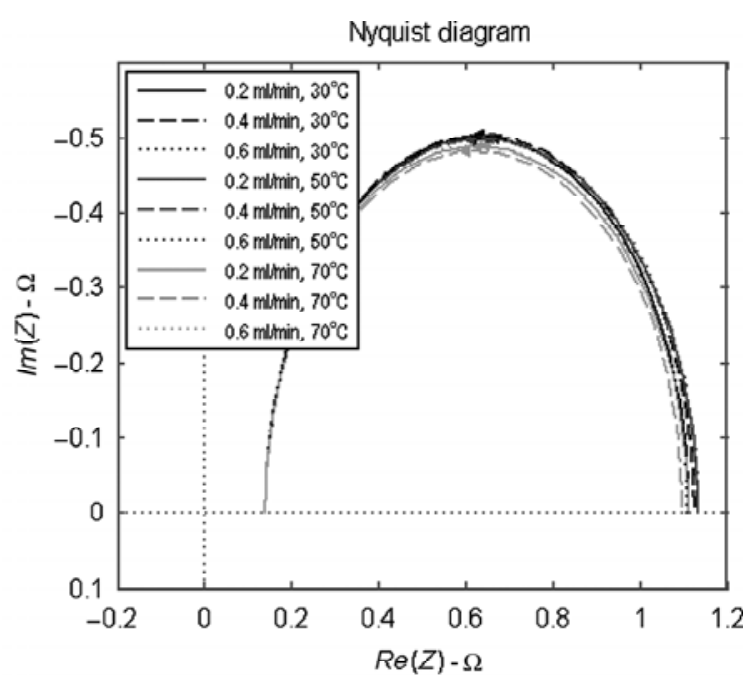

(b)

Figure 8. Nyquist plots of second-order equivalent circuit model's output impedance using component values estimated from: (a) load-on step-responses and (b) load-off step-responses; $1 \mathrm{~mol} / \mathrm{l}$ concentration fuel.

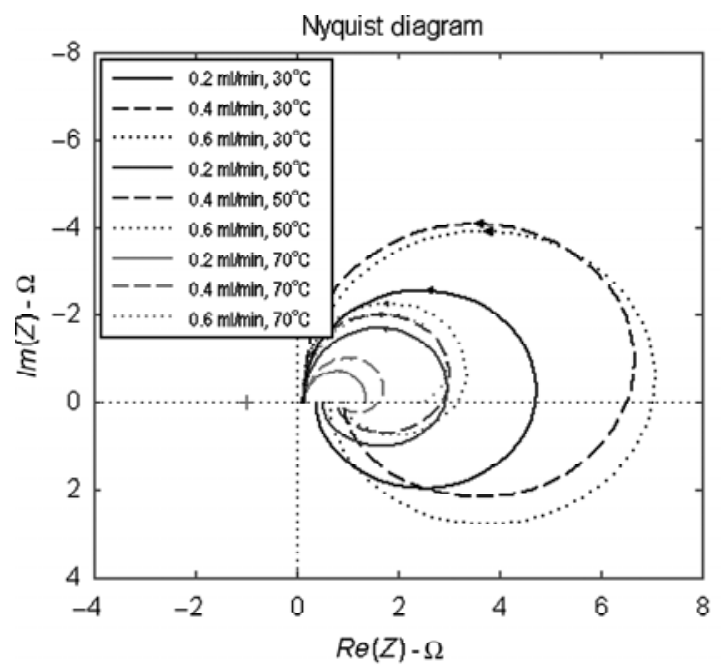

(a)

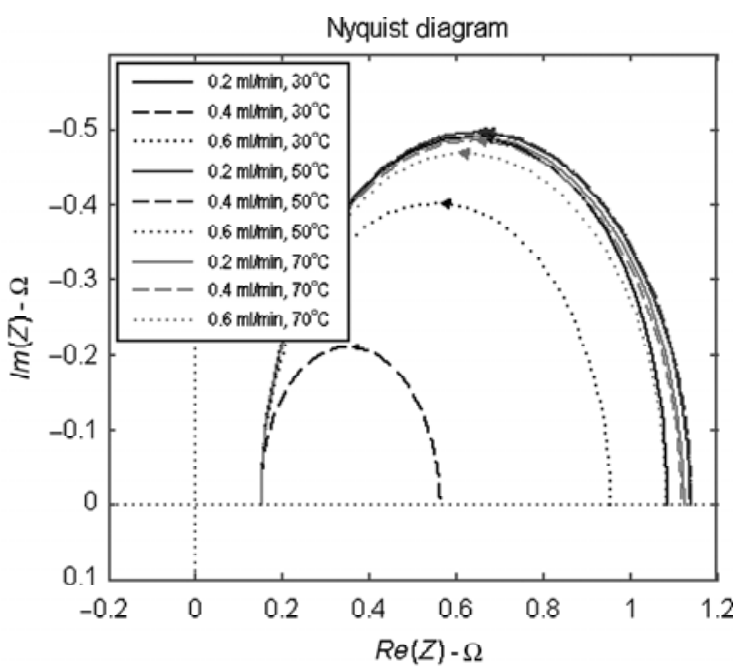

(b)

Figure 9. Nyquist plots of second-order equivalent circuit model's output impedance using component values estimated from: (a) load-on step-responses and (b) load-off step-responses; $0.5 \mathrm{~mol} / \mathrm{l}$ concentration fuel.

The Nyquist plots using the estimates presented in Table 1 are shown as Fig. 8, while the Nyquist plots using the estimates presented in Table 2 are shown as Fig. 9. These plots compare well to the DMFC impedance plots shown in [10], which have similar shapes, and $\operatorname{Re}(Z)$ values ranging from 0 to $5 \Omega$ and $\operatorname{Im}(Z)$ values ranging from -2.5 to $1 \Omega$. These similarities provide a measure of support for the validity of the proposed method and the resulting model component estimates.

\section{Conclusion}

This paper has described the equivalent circuit modelling of DMFC dynamics from measured temporal (time-domain) responses during step-changes in load current at various temperature and fuel flow rate operating conditions. The simulated responses of the assumed second-order circuit model, a first-order model being determined to be less accurate for reproducing the observed response undershoots and overshoots, with its estimated component values yielded excellent fits with the experimental data for the $30-70^{\circ} \mathrm{C}$ temperature range and the $0.2-0.6 \mathrm{ml} / \mathrm{min}$ fuel flow range under study. These results provide all of the information that is obtained by an $\mathrm{AC}$ impedance measurement, without requiring an impedance (frequency response) analyser, and also determines the contribution of each component to the overall impedance. One can use these modelling results in ways such as: (1) diagnostically - to determine which parts of a fuel cell are degrading or have degraded; (2) prospectively - to guide changes to the fuel cell's design and fabrication (such as the MEA's various components) that would improve its output impedance, dynamic behaviour and so on. Perhaps even more importantly, this equivalent circuit model can be used to evaluate and then improve how the DMFC interacts with the other components of the complete power system 
(such as ultracapacitors and switch-mode power converters), for example, the effects of dc-ac converter ripple current on the lifespan of the fuel cell, similar to [6] for $\mathrm{H}_{2}$-fuelled PEMFCs.

It was further determined that the model's capacitor, inductor and resistor values are quite sensitive to temperature but relatively insensitive to fuel flow rates - more so for load-off than for load-on responses - for the same fuel concentration. Moreover, each component's dependencies on temperature and fuel flow rate differ from those of the other components. Such dependencies could mean that in practice, they should be adjusted either statically or dynamically, and in either open-loop or closed-loop fashion, to obtain more optimal performance of DMFCs in applications with fast, frequent and/or significant load changes. In addition, different fuel concentrations resulted in greater variability of the parameter values during the load-on responses as compared to the load-off ones, which is expected as the former corresponds to when current is flowing and thus the fuel consumed to produce that current.

\section{References}

[1] J. Larminie and A. Dicks, Fuel cell systems explained, 2nd ed. (Chichester, England: Wiley, 2003).

[2] Defense, http://www.sfc.com/en/defense.html (last accessed on 22 July, 2011).

[3] Oorja Protonics - Enabling Power, http://www.oorjaprotonics com (last accessed on 22 July, 2011).

[4] Yamaha FC-Dii Fuel Cell Bike Prototype to Premiere at Tokyo Motor Show, http://www.wired.com/gadgetlab/2007/10/ yamaha-fc-dii-f (last accessed on 22 July, 2011).

[5] C.N. Hamelinck and A.P.C. Faaij, Future prospects for production of methanol and hydrogen from biomass, Journal of Power Sources, 111(1), 2002, 1-22.

[6] W. Choi, P.N. Enjeti, and J.W. Howze, Development of an equivalent circuit model of a fuel cell to reduce current ripple, Proc. IEEE Applied Power Electronics Conf., Anaheim, CA, 2004, 355-361.

[7] X. Yan, M. Hou, L. Sun, D. Liang, Q. Shen, H. Xu, P. Ming, and $\mathrm{B}$. $\mathrm{Yi}, \mathrm{AC}$ impedance characteristics of a $2 \mathrm{~kW}$ PEM fuel cell stack under different operating conditions and load changes, International Journal of Hydrogen Energy, 32, 2007, 4358-4364.

[8] A.A. Kulikovsky, Analytical modelling of fuel cells (Oxford, UK: Elsevier, 2010).

[9] T.S. Zhao, K.D. Kreuer, and T.V. Nguyen, Advances in fuel cells (Oxford, UK: Elsevier, 2007).

[10] U. Krewer, System-oriented analysis of the dynamic behaviour of direct methanol fuel cells, Dr.-Ing. Dissertation, Otto von Guericke University, Magdeburg, Germany, 2005.

[11] M. Ordonez, P. Pickup, J.E. Quaicoe, and M.T. Iqbal, Electrical dynamic behavior of a direct methanol fuel cell, IEEE Power Electronics Society Newsletter, 1st quarter, 2007, 10-15.

[12] Y. Wang, J.P. Zheng, G. Au, and E.J. Plichta, A novel method for electrically modeling of fuel cell using frequency response technology: Executed on a direct methanol fuel cell, Proc. 211th ECS Meeting, Chicago, IL, 6-11 May 2007.

[13] J.T. Muller, P.M. Urban, and W.F. Holderich, Impedance studies on direct methanol fuel cell anodes, Journal of Power Sources, 84(2), 1999, 157-160.

[14] D.A. Harrington and B.E. Conway, AC impedance of Faradic reactions involving electrosorbed intermediates: Kinetic theory, Electrochimica Acta, 32(12), 1987, 1703-1712.

[15] W.H. Hayt, Jr., J.E. Kemmerly, and S.M. Durbin, Engineering circuit analysis, 7th ed. (Burr Ridge, IL, USA: McGraw-Hill, Inc., 2007).

\section{Biographies}

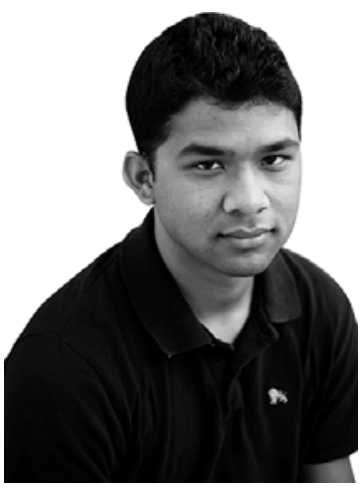

Kshitiz Singh a native of Nepal, graduated in May 2013, is currently a student at Texas Christian University in Fort Worth, TX. He will be receiving his bachelor's degree in engineering with an emphasis in electrical engineering. He has had research experience with fuel cells and fuel cell-based power systems and modeling, analysis and control of signals, circuits and

systems.

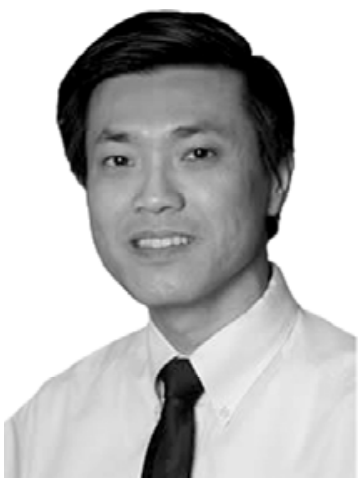

Bill Diong received his B.S., M.S. and $\mathrm{Ph} . \mathrm{D}$. degrees in electrical engineering from the University of Illinois, Urbana-Champaign. He gained valuable practical experience as a senior research engineer with Sundstrand Aerospace (now Hamilton-Sundstrand) before returning to academia. $\mathrm{He}$ is currently an associate professor at Southern Polytechnic State University, Marietta, GA. His research interests include advanced power and energy systems, dynamic systems and control and power electronic systems.

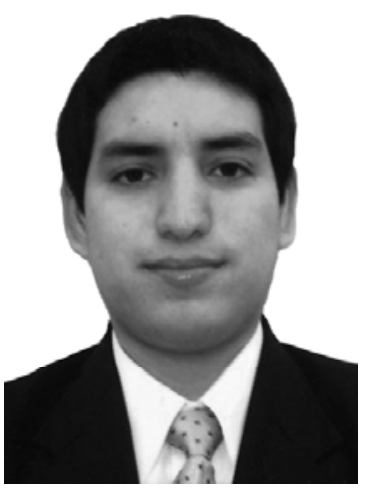

Diego Estrada received his B.S. degree in electrical engineering and a B.A. degree in mathematics from Texas Christian University, Fort Worth, TX, in 2010. He is currently pursuing his M.S. degree in electrical and computer engineering at Baylor University. His research interests include heuristic optimization methods, power plant control systems and multi-agent systems.

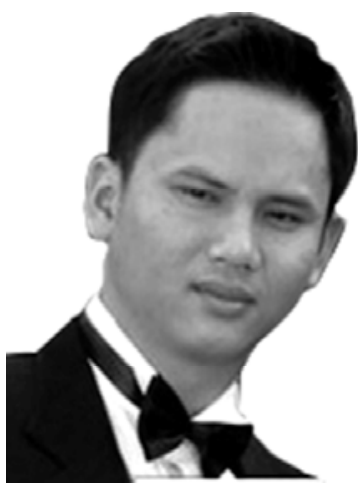

Bao Q. Nguyen graduated in 2012 with a B.S. degree in electrical engineering from Southern Polytechnic State University, Marietta, GA. Since 2012, Nguyen has worked as a signal engineer for National Signal Technology Inc. in Pittsburgh, PA. The company has offices in Atlanta, Louisville, Chicago and Omaha. Nguyen has been elected to "Who's Who Student in American University \& Colleges" in recognition of his outstanding merit and accomplishment as a student at Southern Polytechnic State University. 